\title{
Variation in characteristics of people with mental disorders across smoking status in the Canadian general population
}

\author{
Rudra Dahal', Asmita Bhattarai ${ }^{2}$, Kamala Adhikari $^{2}$
}

\begin{abstract}
INTRODUction People with mental disorders are less successful in smoking cessation efforts. This study compared the characteristics of current smokers and former smokers with mental disorders.

METHODS This was a cross-sectional study that used the Public Use Microdata File of the Canadian Community Health Survey 2012. Survey respondents with any mental health disorder in the last 12 months $(n=2700)$, identified using the World Health Organization Composite International Diagnostic Interview instrument, were included in the analysis. Smoking status was classified based on self-report responses as current, former and never smoker. Logistic regression models were used to analyze the data.

RESULTS The odds of quitting smoking were significantly lower among people who were single or never married (widowed/divorced/separated/single) compared to those who were married or had a common-law partner (adjusted odds ratio, AOR $=0.6,95 \%$ CI: 0.4-0.9). Similarly, significantly lower odds of quitting smoking were observed among people with less than post-secondary education compared to those with post-secondary education (AOR=0.4, 95\% CI: 0.3- 0.6). Also, the odds of quitting were significantly lower among immigrants, young adults, and middle-aged adults.

COnCLUSIONS People who are young or middle-aged, single or never married, less educated, and immigrants, are less likely to quit smoking. This pattern underscores the socioeconomic disparities in quitting smoking among people with mental disorders. Future research should investigate why these groups continue to smoke more often than their counterparts. This will help design the smoking cessation support that address the challenges experienced by vulnerable populations and reduce the disparities.
\end{abstract}

\section{AFFILIATION \\ 1 Faculty of Health Sciences, University of Lethbridge, Lethbridge, Canada 2 Department of Community Health Sciences, University of Calgary, Calgary, Canada}

\section{CORRESPONDENCE TO}

Rudra Dahal. Faculty of Health Sciences, University of Lethbridge, Lethbridge, AB, T1K 3M4, Canada.

E-mail: karsdahal@gmail.com ORCID ID: https://orcid.org/00000001-7911-0779

\section{KEYWORDS}

smoking, quit smoking, mental disorders, socioeconomic characteristics

Received: 29 June 2020

Revised: 24 August 2020

Accepted: 14 September 2020

\section{INTRODUCTION}

Smoking, a modifiable factor, is the leading cause of several preventable chronic diseases (such as cancer, cardiovascular diseases, and respiratory diseases), disability, and death. It is responsible for massive direct and indirect costs, including healthcare costs $^{1,2}$. Smoking is common among vulnerable and socioeconomically disadvantaged groups and is a significant contributor of health inequalities across populations $\mathrm{s}^{3-5}$. The prevalence of smoking, including the severity of smoking (i.e. the average number of cigarettes smoked per day), is higher among people with mental disorders than those without mental disorders $^{6,7}$. This leads to disproportionately higher rates of preventable chronic diseases and deaths in people with mental disorders ${ }^{8}$. Therefore, although the causal direction between mental disorders and smoking is unclear or complex, people with mental disorders are recognized as an important population group for smoking cessation interventions. 
Although most smokers want to quit smoking, many continue smoking as they report that smoking provides them with mental health benefits ${ }^{9,10}$. This issue is even more relevant among people with mental disorders as they experience additional barriers to quit smoking ${ }^{11-14}$. Evidence shows that smoking cessation can be achieved among people with mental illness using the same intervention (behavioral support and pharmacotherapy) that works for the general population ${ }^{15,16}$. Studies have reported that smoking cessation is associated with mental health benefits, that is, reduction in symptoms of mental illness such as depression, anxiety, stress, and improvement in quality of life ${ }^{17}$. Despite this evidence, the proportion of people with smoking cessation (thus the decline in smoking) is lower among those with mental illness than the general population ${ }^{6,7,18}$.

The lower rate of smoking cessation among people with mental disorders may be related to their experience of nicotine withdrawal symptoms during the cessation process, fear that cessation could lead to withdrawal symptoms that they may face, and the perceived benefits of smoking on mental health ${ }^{11-14}$. Furthermore, they may misinterpret the immediate loss of nicotine withdrawal symptoms after smoking as mental health benefits, and do not act to curb or quit smoking. However, taking actions to quit smoking may also depend on their socioeconomic characteristics, vulnerabilities, and preferences to cessation options ${ }^{19,20}$. Therefore, smoking cessation interventions adapted to the needs of an individual with mental disorders might have the greatest impact on reducing the number of smokers and addressing the smoking disparities. To be able to do so, it is essential to distinguish specific populations with mental disorders that are less successful in quitting smoking. This study compared the characteristics of current smokers and former smokers with mental disorders, using a nationally representative community sample in Canada.

\section{METHODS}

\section{Data source}

This is a cross-sectional study that used data from the Public Use Microdata File of the Canadian Community Health Survey-Mental Health (CCHS-MH) 2012, accessed through the University of Calgary webpage (https://library.ucalgary.ca/sands). Detail description of the survey, including data collection methodology, questionnaire, and survey response rate, are available on the website of Statistics Canada ${ }^{21}$. Briefly, the CCHS is a nationally representative cross-sectional survey conducted by Statistics Canada since 2001 . The CCHS collects data on general and contentfocused health status, health behaviors, and healthcare use of the Canadian household populations in a representative sample. The CCHS 2012 was a mental health and well-being content-focused survey of the Canadian household population aged $\geq 15$ years living in the ten provinces $(n=25100 ; n$ is rounded according to the reporting guidelines of Statistics Canada). This survey excluded people who lived in reserves and any other aboriginal settlements, fulltime Canadian armed forces, and people who lived in institutions, altogether accounting for around $3 \%$ of the total Canadian population (CCHS 2012). Given that the Public Use Microdata File of the CCHS is deidentified and publicly available, review and approval by our research ethics board, the Conjoint Health Research Ethics Board at the University of Calgary was not required.

\section{Measures}

People with the presence of any mental health disorder, including major depressive disorder, bipolar disorder, mood disorder, hypomania, generalized anxiety disorder, and substance-dependence (includes alcohol and drug dependence) in the last 12 months, were identified for this study. In the CCHS 2012, these mental health disorders were measured (or diagnosed) using the World Health Organization Composite International Diagnostic Interview (WHOCIDI) instrument ${ }^{21}$. Survey respondents' self-reported smoking status was classified as current smoker, former smoker, and never smoker. Current smoker includes current daily smokers and current occasional smokers. Former smoker includes former daily smokers and former occasional smokers who stopped smoking completely. Other variables of interest were characteristics of people with any mental disorder. These included sociodemographic characteristics (age, sex, marital status, educational attainment, total annual household income, and immigration status), professional consultations/services received, presence of chronic diseases, and physical activity. 


\section{Analysis}

The analysis was limited to survey respondents with any mental health disorders $(n=2700 ; n$ is rounded according to the reporting guidelines of Statistics Canada). The proportion and corresponding confidence interval (95\% CI) of people with mental disorders who were former smokers (i.e. quit smoking), current smokers, and never smokers, were calculated. Bivariate analysis was done to examine the differences in the distribution of characteristics of people with mental disorders across the groups of former smokers, current smokers, and never smokers. The distribution of characteristics, specifically professional consultations/services received, presence of chronic diseases, and physical activity was not different by smoking status among people with mental disorders. These variables were then excluded in the subsequent analysis.

The sociodemographic characteristics, namely age, sex, marital status, educational attainment, immigration status, and total household income status, were further analyzed. The association between these characteristics and smoking status was examined using unadjusted and adjusted multivariable logistic regression analysis. First, we developed logistic regression models in the whole sample, separately for two different smoking outcomes: one being continuing smoker vs nonsmoker and the other being former smoker vs never smoker. To enable us to make a direct comparison between sociodemographic characteristics of former smokers and current smokers, we then developed logistic regression models in the restricted sample of ever smokers $(n=2000 ; n$ is rounded according to the reporting guideline of Statistics Canada). Unadjusted models were developed for individual characteristics. Adjusted models were developed, including all these characteristics in the same model, where every estimated odds ratio (AOR) with 95\% CI was adjusted for every other variable in the model (simultaneous adjustment). In order to compare the findings between those with and without mental disorders, the same models were developed among people without mental disorders as well.

The CCHS survey used stratified, multistage sample selection techniques, which included clustering and unequal selection probabilities.
Survey sampling weights and coefficients of variation, provided by Statistics Canada, were used to ensure the representativeness of the target population and to account for the design effects. All estimates were calculated applying weights, and the CIs for proportions were calculated using the coefficient of variation to compute the margin of error. All analyses were performed using STATA/IC version 14.1. An alpha level of 5\% and the inclusion of null value within the $95 \%$ CIs was used to assess statistical significance.

\section{RESULTS}

Table 1 describes the smoking and sociodemographic characteristics of the survey respondents with the presence of any mental disorders. Of the total 2700 respondents, $37.5 \%$ (95\% CI: 34.0-41.0) were current smokers, 33.6\% (95\% CI: 29.8-37.4) were former smokers, and 28.8\% (95\% CI: 25.4-32.2) were never smokers. The majority of respondents were aged $\leq 45$ years, males, single or never married (includes either widowed or divorced or separated or single), postsecondary graduates, had annual household income $\geq \$ 60000$ (CA\$), and were non-immigrants (Table 1 ).

Table 2 illustrates the distribution of sociodemographic characteristics of people with any mental disorders across their smoking status. Among current smokers, 31.2\% (95\% CI: 26.4-36.0) were aged $15-24$ years, $45.8 \%$ (95\% CI: 39.6-52.0) were females, and 66.3\% (95\% CI: 58.5-74.1) were

Table 1. Characteristics of people with any mental disorders, Canada 2012 ( $\mathrm{N}=2700)$

$\begin{array}{lc}\text { Characteristics } & \%(95 \% \mathrm{CI}) \\ \text { Age (years) } & \\ 15-24 & 29.2(26.3-32.1) \\ 25-34 & 20.6(17.3-23.9) \\ 35-44 & 16.8(13.9-19.7) \\ 45-54 & 16.4(13.5-19.3) \\ 55-64 & 11.6(9.0-34.0) \\ \geq 65 & 5.4(42.4-66.2)\end{array}$

Sex

Male

$51.9(47.6-56.2)$

Female

$48.1(43.8-52.4)$

Marital status

Married/Common law

$40.8(37.1-44.5)$

Widow/divorced/separated or single 
Table 1. Continued

\begin{tabular}{lc} 
Characteristics & $\%(95 \%$ CI $)$ \\
Education status & \\
Less than post-secondary & $47.0(42.8-51.2)$ \\
Post-secondary graduated & $52.8(48.4-57.2)$ \\
Income status (CA $\$)$ & \\
No or <20000 & $8.6(6.4-10.8)$ \\
$20000-39999$ & $15.4(12.8-18.0)$ \\
$40000-59999$ & $18.1(15.3-20.9)$ \\
$60000-79999$ & $17.3(14.5-20.1)$ \\
$\geq 80000$ & $40.5(36.9-44.1)$ \\
Immigration & \\
Yes & $14.1(11.4-16.8)$ \\
No & $85.9(81.9-89.9)$ \\
Smoking status & \\
Current & $37.5(34.0-41.0)$ \\
Former & $33.6(29.8-37.4)$ \\
Never & $28.8(25.4-32.2)$ \\
Moderate/vigorous physical activity & \\
Yes & $73.2(69.8-76.5)$ \\
No & $26.8(22.9-30.6)$ \\
Chronic conditions & \\
At least one & $58.3(53.5-63.1)$ \\
None & $41.7(37.9-45.5)$ \\
Mental health consultation & \\
Yes & $45.2(41.1-49.3)$ \\
No & $54.8(51.1-58.5)$ \\
Cl: confidence interval, corrected using the coefficient of variations provided by \\
\hline
\end{tabular}

single or never married. Similarly, 59.6\% (95\% CI: 52.6-66.6) of smokers had less than post-secondary education, $12.1 \%$ (95\% CI: 8.3-15.9) had household income $\leq \$ 20000$, and $12.1 \%$ (95\% CI: $7.8-16.4$ ) were immigrants. Whereas, among former smokers, $21.1 \%$ (95\% CI: $16.2-26.0$ ) were aged $15-24$ years, $43.2 \%$ (95\% CI: 37.0-49.4) were females, and $49.3 \%$ (95\% CI: 42.6-56.0) were single or never married. Similarly, 37.7\% (95\% CI: 31.2-44.2) of former smokers had less than post-secondary education, 7.2\% (95\% CI: 4.0-10.4) had household income $\leq \$ 20000$, and $8.4 \%$ (95\% CI: $4.9-11.9)$ were immigrants.

Table 3 shows the association between sociodemographic characteristics and smoking status of people with mental disorders. The odds of smoking were significantly higher among those who were aged 25-64 years compared to those aged $\geq 65$ years $(\mathrm{AOR}=2.6-3.4)$ and those who had less than post-secondary education compared to those who had post-secondary education $(\mathrm{AOR}=2.3$, 95\% CI: 1.6-3.2). Also, the odds of smoking were significantly higher among those with household income $\leq \$ 20000$ compared to those with $\geq \$ 80000$ (AOR $=2.7,95 \%$ CI: $1.5-2.4)$. The odds of smoking among females compared to males (AOR $=0.6,95 \%$ CI: 0.4-0.8) and among immigrants compared to Canadian born (AOR=0.5, 95\% CI: 0.3-0.7) were significantly lower. The odds of quitting smoking

Table 2. Characteristics of people with any mental disorders across smoking status, Canada 2012 (N=2700)

\begin{tabular}{|c|c|c|c|}
\hline \multirow[t]{2}{*}{ Characteristics } & \multicolumn{3}{|c|}{ Smoking status } \\
\hline & $\begin{array}{c}\text { Current } \\
\%(95 \% \text { CI })\end{array}$ & $\begin{array}{c}\text { Former or quitted } \\
\quad \%(95 \% \text { CI })\end{array}$ & $\begin{array}{c}\text { Never } \\
\%(95 \% \text { CI })\end{array}$ \\
\hline \multicolumn{4}{|l|}{ Age (years) } \\
\hline $15-24$ & $31.2(26.4-36.0)$ & $21.1(16.2-26.0)$ & $35.9(30.1-41.7)$ \\
\hline $25-34$ & $23.0(17.2-28.8)$ & $19.3(13.5-25.1)$ & $18.9(13.2-24.6)$ \\
\hline $35-44$ & $16.7(11.7-21.7)$ & $16.4(11.4-21.4)$ & $17.1(11.5-22.7)$ \\
\hline $45-54$ & $16.1(11.1-21.1)$ & $20.1(14.1-26.1)$ & $12.4(7.5-17.3)^{\mathrm{a}}$ \\
\hline $55-64$ & $10.5(6.4-14.6)^{\mathrm{a}}$ & $14.5(9.5-19.5)^{\mathrm{a}}$ & $9.8(5.3-14.3)^{\mathrm{a}}$ \\
\hline$\geq 65$ & $2.4(1.1-3.7)^{\mathrm{a}}$ & $8.4(5.8-11.0)$ & $5.8(3.5-8.1)^{\mathrm{a}}$ \\
\hline \multicolumn{4}{|l|}{ Sex } \\
\hline Male & $54.2(47.8-60.6)$ & $56.8(50.1-63.5)$ & $43.3(36.1-50.5)$ \\
\hline Female & $45.8(39.6-52.0)$ & $43.2(37.0-49.4)$ & $56.7(49.7-63.7)$ \\
\hline \multicolumn{4}{|l|}{ Marital status } \\
\hline Married/Common law & 33.7 (27.6-39.8) & $50.7(44.4-57.0)$ & $38.6(32.0-45.2)$ \\
\hline
\end{tabular}


Table 2. Continued

Characteristics

Smoking status

Current

Former or quitted

Never

$\%(95 \%$ CI $)$ $\%(95 \% \mathrm{CI})$

$\%(95 \%$ CI $)$

Widow/divorced/separated or single

Education status

Less than post-secondary

Post-secondary graduated

Income status (CA\$)

No or $<20000$

20000-39999

40000-59999

60000-79999

$\geq 80000$

Immigration

Yes

No

Moderate/vigorous physical activity

Yes

No

Chronic condition

At least one

None

Mental health consultation

Yes

No

$66.3(58.5-74.1)$
$59.6(52.6-66.6)$
$40.4(34.6-46.2)$

$12.1(8.3-15.9)$

$19.3(13.9-24.7)$

18.9 (13.6-24.2)

13.8 (9.5-18.1)

$35.9(30.2-41.6)$

$12.1(7.8-16.4)^{\mathrm{a}}$

$87.9(81.4-94.4)$

$71.2(64.8-77.6)$

$28.8(22.9-34.7)$

58.5 (51.6-65.4)

$41.5(35.5-47.5)$

$43.3(37.1-49.5)$

$56.7(50.0-63.4)$
$49.3(42.6-56.0)$
$37.7(31.2-44.2)$

61.4(53.8-69.0)

$42.0(35.0-49.0)$

$57.9(50.7-65.1)$

$7.2(4.0-10.4)^{\mathrm{a}}$

$5.9(2.7-9.1)^{\mathrm{a}}$

$11.8(7.6-16.0)^{\mathrm{a}}$

16.6(11.8-21.4)

$22.2(17.0-27.4)$

$14.4(9.3-19.5)^{\mathrm{a}}$

18.9 (13.6-24.2)

16.1 (11.2-21.0)

$44.7(37.8-51.6)$

42.1 (35.6-46.6)

$23.2(23.2-29.5)$

76.9 (70.0-83.8)

$91.6(87.8-95.4)$

4.6 (67.9-81.3)

74.3 (67.6-81.0)

$25.4(19.6-31.2)$

$25.7(19.8-31.6)$

56.9 (49.8-64.0)

$59.3(52.3-66.3)$

$43.1(35.9-50.3)$

$40.7(34.4-47.0)$

$45.4(38.9-51.9)$

$47.4(40.1-54.7)$

$54.6(48.2-61.0)$

a The coefficient of variation is in the marginal range, i.e. 16.6\% - 33.3\%. As suggested by Statistics Canada, the estimate should be interpreted with caution as there is high sampling variability associated with them. Cl: confidence intervals corrected using the coefficient of variations provided by Statistics Canada.

Table 3. Association between characteristics of people with any mental disorders and their smoking status, Canada $2012(\mathrm{~N}=2700)$

\section{Age (years)}

\begin{tabular}{|c|c|c|c|c|}
\hline $15-24$ & $2.1(1.1-4.1)$ & $1.6(0.8-3.3)$ & $0.4(0.2-0.8)$ & $0.3(0.2-0.7)$ \\
\hline $25-34$ & $2.9(1.4-6.2)$ & $3.2(1.5-6.6)$ & $0.7(0.3-1.5)$ & $0.5(0.3-1.1)$ \\
\hline $35-44$ & $2.3(1.1-4.9)$ & $3.0(1.4-6.2)$ & $0.7(0.3-1.3)$ & $0.5(0.2-1.0)$ \\
\hline $45-54$ & $3.1(1.4-6.8)$ & $3.4(1.6-7.2)$ & $1.1(0.5-2.3)$ & $0.9(0.4-1.8)$ \\
\hline $55-64$ & $2.6(1.2-5.5)$ & $2.6(1.3-5.4)$ & $1.0(0.5-2.1)$ & $0.8(0.4-1.7)$ \\
\hline$\geq 65$ & Ref. & Ref. & Ref. & Ref. \\
\hline \multicolumn{5}{|l|}{ Sex } \\
\hline Female & $0.6(0.5-0.9)$ & $0.6(0.4-0.8)$ & $0.6(0.4-0.8)$ & $0.5(0.4-0.7)$ \\
\hline Male & Ref. & Ref. & Ref. & Ref. \\
\hline \multicolumn{5}{|l|}{ Marital status } \\
\hline Widow/divorced/separated or single & $1.2(0.9-1.7)$ & $1.1(0.7-1.6)$ & $0.6(0.4-0.8)$ & $0.8(0.5-1.1)$ \\
\hline Married/Common law & Ref. & Ref. & Ref. & Ref. \\
\hline
\end{tabular}


Table 3. Continued

\begin{tabular}{|c|c|c|c|c|}
\hline \multirow[t]{2}{*}{ Characteristics } & \multicolumn{2}{|c|}{ Current smoker vs never smoker } & \multicolumn{2}{|c|}{ Former smoker vs never smoker } \\
\hline & OR $(95 \% \mathrm{CI})$ & $\operatorname{AOR}(95 \% \mathrm{CI})$ & OR $(95 \% \mathrm{CI})$ & AOR $(95 \% \mathrm{CI})$ \\
\hline \multicolumn{5}{|l|}{ Education status } \\
\hline Less than post-secondary & $2.0(1.5-2.8)$ & $2.3(1.6-3.2)$ & $0.8(0.6-1.2)$ & $0.9(0.6-1.3)$ \\
\hline Post-secondary graduated & Ref. & Ref. & Ref. & Ref. \\
\hline \multicolumn{5}{|l|}{ Income status (CA\$) } \\
\hline No or $<20000$ & $2.6(1.5-4.4)$ & $2.7(1.5-4.7)$ & $1.3(0.7-2.2)$ & $1.6(0.9-3.0)$ \\
\hline 20000-39999 & $1.7(1.1-2.6)$ & $1.6(1.0-2.6)$ & $0.9(0.6-1.4)$ & $1.0(0.6-1.6)$ \\
\hline 40000-59999 & $1.3(0.8-2.0)$ & $1.5(0.9-2.4)$ & $0.9(0.6-1.5)$ & $1.0(0.6-1.6)$ \\
\hline 60000-79999 & $1.1(0.7-1.7)$ & $1.1(0.7-1.8)$ & $1.5(0.9-2.3)$ & $1.5(0.9-2.4)$ \\
\hline$\geq 80000$ & Ref. & Ref. & Ref. & Ref. \\
\hline \multicolumn{5}{|l|}{ Immigration } \\
\hline Yes & $0.5(0.3-0.7)$ & $0.5(0.3-0.7)$ & $0.3(0.2-0.5)$ & $0.2(0.1-0.4)$ \\
\hline No & Ref. & Ref. & Ref. & Ref. \\
\hline
\end{tabular}

OR: odds ratio. AOR: adjusted odds ratio. Cl: confidence interval.

among those aged 15-24 years compared to those aged 65 years $(\mathrm{AOR}=0.3,95 \% \mathrm{CI}: 0.2-0.7)$ was significantly lower. Similarly, the odds of quitting smoking among females compared to males (AOR $=0.5$, 95\% CI: 0.4-0.7) and among immigrants compared to Canadian born (AOR=0.2, 95\% CI: $0.1-$ 0.4 ) were significantly lower.

Table 4 illustrates the association between sociodemographic characteristics of people with mental disorders and their smoking status, restricted to ever smokers only. The findings from this restricted sample analysis are similar to the findings in Table 3 that resulted from the full sample analysis, including ever smokers and never smokers. Respondents aged $<65$ years compared to those who were $<65$ years were significantly less likely to quit smoking $(\mathrm{AOR}=0.2-0.3)$. Similarly, immigrants (AOR=0.6, 95\% CI: 0.4-0.9), those with less than post-secondary education $(\mathrm{AOR}=0.4,95 \%$ CI: $0.3-$ $0.6)$, and those who were single or never married (AOR=0.6, 95\% CI: 0.4-0.9) were less likely to quit smoking. Although the estimates of OR failed to reach statistical significance in some of the categories of income (probably lacked power due to small sample size), we can still see a pattern in them that as the income level increases, people are relatively more likely to quit smoking (in comparison to the highest income group). Overall, the patterns of association between sociodemographic characteristics and
Table 4. Association between characteristics of people with any mental disorders who were ever smokers and their smoking status, Canada 2012 ( $N=2000)$

Characteristics

Former smoker vs current smoker (restricted analysis)

OR $(95 \% \mathrm{CI})$

AOR $(95 \%$

CI)

\section{Age (years)}

15-24

$0.2(0.1-0.3)$

$0.2(0.1-0.4)$

25-34

$0.2(0.1-0.4) \quad 0.2(0.1-0.4)$

35-44

$0.3(0.2-0.5)$

$0.2(0.1-0.4)$

45-54

$0.4(0.2-0.7) \quad 0.3(0.1-0.5)$

55-64

$0.4(0.2-0.7)$

$0.3(0.2-0.6)$

$\geq 65$

Ref.

Ref.

Sex

Female

Male

$0.9(0.7-1.2)$

$0.9(0.6-1.2)$

Ref.

Ref.

Marital status

Widow/divorced/separated or single

Married/Common law

Education status

Less than post-secondary

Post-secondary graduated

Income status (CA\$)

No or $<20000$

$0.5(0.4-0.7) \quad 0.6(0.4-0.9)$

20000-39999

40000-59999

Ref.

Ref.

60000-79999

$\geq 80000$

$\begin{array}{cc}0.4(0.3-0.5) & 0.4(0.3-0.6) \\ \text { Ref. } & \text { Ref. } \\ 0.5(0.3-0.8) & 0.7(0.4-1.1) \\ 0.5(0.4-0.8) & 0.6(0.4-0.9) \\ 0.7(0.5-1.1) & 0.8(0.5-1.2) \\ 1.4(0.9-2.1) & 1.5(1.0-2.3) \\ \text { Ref. } & \text { Ref. }\end{array}$

Continued 
Table 4. Continued

$\begin{array}{lcc}\text { Characteristics } & \begin{array}{c}\text { Former smoker vs current } \\ \text { Smoker (restricted analysis) }\end{array} \\ \text { OR }(95 \% \text { CI) } & \text { AOR }(95 \% \\ \text { CI })\end{array}$

OR: odds ratio. AOR: adjusted odds ratio. Cl: confidence interval.

smoking status (former vs current smoker) among people with mental disorders were similar to those without mental disorders. Notably, those with less than post-secondary education and immigrants were more likely to continue smoking if they had mental disorders (Supplementary file, Table S1).

\section{DISCUSSION}

This cross-sectional study examined the characteristics of current smokers and former smokers with mental disorders, using the nationally representative community-based data in Canada. This study found that a higher proportion of people with mental disorders were current smokers (37.5\%) than former smokers $(33.6 \%)$. Among the people with mental disorders, immigrants (compared to Canadian-born group) and those who were single or never married (compared to married or living with a common-law partner) were less likely to quit smoking by $40 \%$. Similarly, people with less than post-secondary education and those who were young and middleaged adults were less likely to quit smoking than postsecondary graduates and elderly.

Consistent with our study findings, other studies have found a disproportionately higher prevalence of smoking and a lower prevalence of quitting among those who have a mental illness than the general population $^{22-24}$. In 2019 , the prevalence of current smokers was $15 \%$ and that of former smokers was $26 \%$, in the general Canadian population ${ }^{22}$. In our analysis of people with no mental disorders, we found $19.1 \%$ were current smokers and $39.3 \%$ were former smokers. In the UK, among groups with and without mental illness, the prevalence of current smokers was $34.1 \%$ and $22.3 \%$, respectively, and the prevalence of former smokers was $49.4 \%$ and $66.2 \%$, respectively ${ }^{25}$.

Importantly, our study findings provide insight into the socioeconomic characteristics of people with mental disorders who continued or quit smoking. The observed socioeconomic differences in smoking cessation were similar between people with and without mental disorders and are consistent with previous findings on people with mental illness and in the general population ${ }^{6,26,27}$. The disproportionally high number of smokers in the group with mental disorders, along with the socioeconomic disparities, indicates that existing smoking cessation programs are not sufficiently able to meet the smoking cessation needs of vulnerable populations. People with mental disorders have many of the same barriers for smoking cessation as people with no mental disorders, such as fear of withdrawal, weight gain, and cessation failure ${ }^{11,14}$. However, evidence also suggests that people with mental disorders face additional challenges ${ }^{11-14}$.

People with mental disorders are more likely to be severe smokers, have high levels of nicotine exposure and dependence, and experience severe nicotine withdrawal symptoms than people with no mental disorders ${ }^{12,13}$. Hence, they face more considerable difficulties in quitting smoking. Additionally, people with mental disorders choose to smoke as a self-medication to cope with the effects of mental disorders ${ }^{11}$, a practice that has been positively reinforced due to the widely held belief that smoking benefits mental health. Health professionals may also hesitate to intervene if they believe that stopping smoking is detrimental to their mental health ${ }^{28}$. As a result, people with mental disorders are less successful in quitting (or sustained abstinence), and their smoking cessation need remains unmet. However, it is important to realize that although people find smoking (self-medication) helpful in immediately relieving the symptoms of anxiety or depression, it creates the false perception that smoking has psychological benefits; this may be part of the nicotine withdrawal feedback mechanism. It is smoking that causes the psychological disturbances in the first place. Strong evidence suggests that cessation in fact improves mental health ${ }^{17}$.

The unmet smoking cessation needs of people with mental disorders are even worse in those who are socially deprived, such as people who are less 
educated, have low incomes, and are immigrants, as they face a less supportive environment that makes their smoking cessation more challenging. The challenges include less access to cessation support (due to, for example, financial constraints, language barriers, less access to resources for cessation, and less knowledge about smoking cessation support measures) and low family or social support ${ }^{3,4,27}$. Additionally, the high levels of nicotine exposure and dependence, and the severity of mental disorders in this group may make their smoking cessation process less successful ${ }^{29}$. And, this disappointment could worsen their mental health status ${ }^{30,31}$. Nonetheless, the occurrence of disparities within the population with the same clinical condition (mental disorders) who are at increased risk for smoking behavior, and the additional disparities among immigrants and less educated people with mental disorders compared to those with no mental disorders, is intolerable.

This study raises important research questions: why people with certain characteristics were (or were not) successful in quitting smoking than others, and why the immigrants and less educated people with mental disorders were particularly less successful in quitting than those without mental disorders. Future studies performing the prospective longitudinal assessment of mental disorders, including the severity, smoking behaviors, cessation attempts, and nicotine withdrawal syndromes among advantaged and disadvantaged people with mental disorders, may provide a clear understanding of the mechanism between mental disorders and cessation. Similarly, in-depth examination of multilevel barriers and enablers for smoking cessation (individual, interpersonal, socioenvironmental, cessation support programs and practices) experienced by those groups may help clarify their vulnerabilities and needs. The findings from these analyses will eventually guide the design and implementation of cessation interventions that meet the cessation needs of vulnerable populations. We were unable to analyze any of these due to data limitations.

Our finding on the characteristics of people with mental problems who are less likely to quit smoking is important for public health workers, including decisionmakers or policymakers. The finding will guide them in allocating resources for research and the design of cessation interventions or the cessation service practices focusing on those people. As the disadvantaged population with mental disorders who smoke represents a subset of smokers, they require specialized cessation support. Populationbased smoking cessation interventions help reduce the smoking prevalence at the population level and improve overall population health ${ }^{32,33}$. However, not everyone benefits equally from these interventions and instead, sometimes increase the health disparities. Population at-risk cessation intervention approaches target to reduce the smoking exposure for individuals at higher risk, but do not address the disparities between the socially defined groups ${ }^{32,33}$. This justifies or necessitates the use of a vulnerable population approach for smoking cessation. This approach aims to decrease the smoking-related inequalities by using tailored, personalized smoking cessation strategies that are responsive to their cessation needs, and changing the social conditions that make the vulnerable population at higher risk of continuing smoking ${ }^{33}$. A significant proportion of people, specifically disadvantaged people, experience mental health concerns in their lifetime and smoking behavior is highly concentrated in this group. The vulnerable population-based cessation intervention approach might be beneficial to diminish the smoking-related disparities, and also to reduce the overall burden of smoking. For example, integrating smoking cessation support into the existing mental health services and tailoring it to the needs of the vulnerable population seem crucial.

\section{Strengths and limitations}

This study has several strengths and limitations, which need to be acknowledged to be able to make inferences from the findings. This study analyzed data from the nationally representative community samples, leading to considerable generalizability of the study findings in the Canadian general population. Important to note that $3 \%$ of the total Canadian population that represents people living in reserves, full-time members of Canadian forces, residents of remote areas, and residents of health institutions, were not included in this survey. These populations are in fact more vulnerable to mental disorders and social disadvantages. While the inclusion of this population may not change our findings given the 
small proportion they represent, the findings are not generalizable to this specific population. The survey measured a wide range of mental disorders (major depressive disorder, bipolar, mood disorder, hypomania, generalized anxiety disorder, and substance dependence) using a standardized tool. However, we analyzed the presence of any mental disorders that include these mental disorders; hence, our findings are less specific to a particular mental disorder.

Similarly, as the data on smoking status were based on self-report, smoking status may have been misclassified. The variations in characteristics of people with any mental disorders who smoke and quit are possibly related to the differences in severity of mental disorders. Some of our estimates, mainly, the estimates corresponding to age, income, and immigration, should be interpreted with caution due to the associated high sampling variability attributable to a small sample size.

\section{CONCLUSIONS}

This study found that the characteristics of people with mental disorders differ in current smokers and former smokers. Smoking cessation was low in young people, people living without partners or spouses, less educated people, and immigrants, compared to their respective counterparts. The observed socioeconomic disparities in smoking cessation among people with mental disorders may be related to the additional barriers or vulnerabilities experienced by the socioeconomically disadvantaged population. As opposed to the population-based and population atrisk intervention approaches, the targeted smoking cessation approach for the vulnerable population enables the design and implementation of smoking cessation programs targeted to the smoking cessation needs of vulnerable groups, which might be beneficial to reduce the disparities. Future research aiming to improve the understanding of why disadvantaged people with mental disorders choose to continue smoking will be valuable to inform cessation interventions specific to vulnerable populations.

\section{REFERENCES}

1. Alam S, Lang JJ, Drucker AM, et al. Assessment of the burden of diseases and injuries attributable to risk factors in Canada from 1990 to 2016: an analysis of the Global Burden of Disease Study. CMAJ Open. 2019;7(1):E140-E148. doi:10.9778/cmajo.20180137

2. Centers for Disease Control and Prevention. Annual smoking attributable mortality, years of potential life lost and productivity losses-United States, 1997-2001. MMWR Morb Mortal Wkly Rep. 2005;54(25):625-628. PMID:15988406.

3. Chaiton M, Callard C. Mind the Gap: Disparities in Cigarette Smoking in Canada. Tob Use Insights. 2019;12:1179173x19839058. doi:10.1177/1179173x19839058

4. Lund M, Lund KE, Rise J. [Socioeconomic differences in smoking cessation among adults]. Tidsskr Nor Laegeforen. 2005;125(5):564-568. PMID:15776027.

5. Jha P, Peto R, Zatonski W, Boreham J, Jarvis MJ, Lopez AD. Social inequalities in male mortality, and in male mortality from smoking: indirect estimation from national death rates in England and Wales, Poland, and North America. Lancet. 2006;368(9533):367-370. doi:10.1016/s0140-6736(06)68975-7

6. Cook BL, Wayne GF, Kafali EN, Liu Z, Shu C, Flores $\mathrm{M}$. Trends in smoking among adults with mental illness and association between mental health treatment and smoking cessation. JAMA. 2014;311(2):172-182. doi:10.1001/jama.2013.284985

7. Lawrence D, Mitrou F, Zubrick SR. Smoking and mental illness: results from population surveys in Australia and the United States. BMC Public Health. 2009;9(1):285. doi:10.1186/1471-2458-9-285

8. Callaghan RC, Veldhuizen S, Jeysingh T, et al. Patterns of tobacco-related mortality among individuals diagnosed with schizophrenia, bipolar disorder, or depression. J Psychiatr Res. 2014;48(1):102-110. doi:10.1016/j.jpsychires.2013.09.014

9. Hymowitz N, Cummings KM, Hyland A, Lynn WR, Pechacek TF, Hartwell TD. Predictors of smoking cessation in a cohort of adult smokers followed for five years. Tob Control. 1997;6(Suppl 2):S57-S62. doi:10.1136/tc.6.suppl_2.s57

10. Zhou X, Nonnemaker J, Sherrill B, Gilsenan AW, Coste F, West R. Attempts to quit smoking and relapse: factors associated with success or failure from the ATTEMPT cohort study. Addict Behav. 2009;34(4):365-373. doi:10.1016/j.addbeh.2008.11.013

11. Keller-Hamilton B, Moe AM, Breitborde NJK, Lee A, Ferketich AK. Reasons for smoking and barriers to cessation among adults with serious mental illness: A qualitative study. J Community Psychol. 2019;47(6):1462-1475. doi:10.1002/jcop.22197

12. Smith PH, Homish GG, Giovino GA, Kozlowski LT. Cigarette smoking and mental illness: a study of nicotine withdrawal. Am J Public Health. 2014;104(2):e127-e133. doi:10.2105/ajph.2013.301502

13. Weinberger AH, Kashan RS, Shpigel DM, et al. Depression and cigarette smoking behavior: A critical review of population-based studies. Am J Drug Alcohol Abuse. 
2017;43(4):416-431. doi:10.3109/00952990.2016.1171327

14. Twyman L, Bonevski B, Paul C, Bryant J. Perceived barriers to smoking cessation in selected vulnerable groups: a systematic review of the qualitative and quantitative literature. BMJ Open. 2014;4(12):e006414. doi:10.1136/bmjopen-2014-006414

15. Gilbody S, Peckham E, Bailey D, et al. Smoking cessation for people with severe mental illness (SCIMITAR+): a pragmatic randomised controlled trial. Lancet Psychiatry. 2019;6(5):379-390. doi:10.1016/S2215-0366(19)30047-1

16. Peckham E, Brabyn S, Cook L, Tew G, Gilbody S. Smoking cessation in severe mental ill health: what works? an updated systematic review and meta-analysis. BMC Psychiatry. 2017;17(1):252. doi:10.1186/s12888-017-1419-7

17. Taylor G, McNeill A, Girling A, Farley A, Lindson-Hawley $\mathrm{N}$, Aveyard $\mathrm{P}$. Change in mental health after smoking cessation: systematic review and meta-analysis. BMJ. 2014;348:g1151. doi:10.1136/bmj.g1151

18. Patten SB, Williams JVA, Lavorato DH, Wang JL, Sajobi TT, Bulloch AGM. Major depression and non-specific distress following smoking cessation in the Canadian general population. J Affect Disord. 2017;218:182-187. doi:10.1016/j.jad.2017.04.056

19. Rae J, Pettey D, Aubry T, Stol J. Factors affecting smoking cessation efforts of people with severe mental illness: a qualitative study. J Dual Diagn. 2015;11(1):42-49. doi:10.1080/15504263.2014.992096

20. Georgiadou C, Lavdaniti M, Psychogiou M, Tzenalis A, Sgantzos M, Sapountzi-Krepia D. Factors affecting the decision to quit smoking of the participants of a hospitalbased smoking cessation program in Greece. J Caring Sci. 2015;4(1):1-11. doi:10.5681/jcs.2015.001

21. Statistics Canada. Canadian Community Health SurveyAnnual Component (CCHS). https://www23.statcan. gc.ca/imdb/p2SV.pl?Function=getSurvey\&Id=135927. Published November 28, 2012. Accessed April 30, 2020.

22. Government of Canada. Canadian tobacco, alcohol and drugs survey (CTADS):summary of results for 2017. https://www.canada.ca/en/health-canada/services/ canadian-tobacco-alcohol-drugs-survey/2017-summary. html. Updated January 1, 2019. Accessed August 21, 2020.

23. Prochaska JJ, Das S, Young-Wolff KC. Smoking, Mental Illness, and Public Health. Annu Rev Public Health. 2017;38(1):165185. doi:10.1146/annurev-publhealth-031816-044618

24. Diaz FJ, Rendon DM, Velásquez DM, Susce MT, de Leon J. Datapoints: Smoking and smoking cessation among persons with severe mental illnesses. Psychiatr Serv. 2006;57(4):462. doi:10.1176/ps.2006.57.4.462

25. Richardson S, McNeill A, Brose LS. Smoking and quitting behaviours by mental health conditions in Great Britain (1993-2014). Addict Behav. 2019;90:14-19. doi:10.1016/j.addbeh.2018.10.011

26. McIvor A. Tobacco control and nicotine addiction in Canada: current trends, management and challenges. Can
Respir J. 2009;16(1):21-26. doi:10.1155/2009/485953

27. Broms U, Silventoinen K, Lahelma E, Koskenvuo M, Kaprio J. Smoking cessation by socioeconomic status and marital status: the contribution of smoking behavior and family background. Nicotine Tob Res. 2004;6(3):447455. doi:10.1080/14622200410001696637

28. McNally L, Oyefeso A, Annan J, et al. A survey of staff attitudes to smoking-related policy and intervention in psychiatric and general health care settings. J Public Health. 2006;28(3):192-196. doi:10.1093/pubmed/fdl029

29. Chen A, Machiorlatti M, Krebs NM, Muscat JE. Socioeconomic differences in nicotine exposure and dependence in adult daily smokers. BMC Public Health. 2019;19(1):375. doi:10.1186/s12889-019-6694-4

30. Kim SJ, Chae W, Park WH, Park MH, Park EC, Jang SI. The impact of smoking cessation attempts on stress levels. BMC Public Health. 2019;19(1):267. doi:10.1186/s12889-019-6592-9

31. McDermott MS, Marteau TM, Hollands GJ, Hankins M, Aveyard P. Change in anxiety following successful and unsuccessful attempts at smoking cessation: cohort study. Br J Psychiatry. 2013;202(1):62-67. doi:10.1192/bjp.bp.112.114389

32. Rose G. Sick individuals and sick populations. Int J Epidemiol. 2001;30(3):427-432. doi:10.1093/ije/30.3.427

33. Frohlich KL, Potvin L. Transcending the known in public health practice: The inequality paradox: The population approach and vulnerable populations. Am J Public Health. 2008;98(2):216-221. doi:10.2105/ajph.2007.114777

CONFLICTS OF INTEREST

The authors have completed and submitted the ICMJE Form for Disclosure of Potential Conflicts of Interest and none was reported.

\section{FUNDING}

There was no source of funding for this research.

PROVENANCE AND PEER REVIEW

Not commissioned; externally peer reviewed. 